\title{
A Plant-Based Diet Prevents and Treats Prostate Cancer
}

\author{
Stewart Rose and Amanda Strombom* \\ Plant-Based Diets in Medicine, USA
}

Submission: June 20, 2018; Published: July 12, 2018

*Correspondence Address: Stewart Rose, Vice President, Plant-Based Diets in Medicine, 15100 SE 38th St, \#820, Bellevue, WA 98006, Tel: 425531 2829; Email: contact@pbdmedicine.org

Abstract

This review covers research done on the prevention and treatment of prostate cancer with a plant-based diet. Epidemiological studies have strongly implicated diet as a major modulator of prostate cancer risk. The risk of prostate cancer in vegetarians is less than half of nonvegetarians. While plant-based foods have been shown to decrease the risk of prostate cancer, animal-derived foods increase the risk it in a dose dependent manner. Intake of saturated fat and cholesterol found in animal derived foods are independent risk factors for prostate cancer, contributing further to the higher risk that nonvegetarians have.

Other risk factors include a higher intake of carcinogenic persistent organic pollutants that bioconcentrate in animal adipose tissue and known carcinogens such as heterocyclic amines and polycyclic aromatic hydrocarbons that result from consuming cooked, fried, or barbecued meats. Persistent organic pollutants have been shown to be etiologic factors. Interventional studies have shown that a plant-based diet effectively halted or slowed the progression of most prostate cancer patients with a Gleason Score of less than seven. Results were maintained over a fouryear period. Active tumor suppression for patients paced on a plant-based diet have been demonstrated. While many patients are placed on a passive watchful waiting protocol adding a plant- based diet can transform the protocol to active treatment.

Keywords: Carcinogens; Cholesterol; Heterocyclic amines; Isothiocyanate Sulforaphane; Lycopene; Persistent organic pollutants; Plant-based diet; Polycyclic aromatic hydrocarbons; Prostate cancer; Vegan; Vegetarian; Watchful waiting

\section{Introduction}

Both patients and physicians are increasingly interested in the use of a healthy vegetarian diet composed fruits, vegetables, legumes, nuts and whole grains for the prevention and treatment of prostate cancer. This article discusses the research and the clinical application of vegetarian nutritional medicine to the prevention and treatment of prostate cancer. Research has shed light on animal derived foods in the diet as a risk factor, and the value of plant foods in reducing the incidence of prostate cancer. The role of different constituents of animal derived foods in the pathogenesis of prostate cancer has also been studied, as have the chemoprotective properties of different plant foods.

Interventional studies using a plant-based diet in the treatment of early-stage low-grade prostate cancer have also been conducted. These studies document a dose response relationship between diet change and tumor suppression, strengthening the evidence for the efficacy of the treatment. Also studied are differences in gene expression between cancer patients treated with a plant- based diet and those in the control group, thus offering some biochemical basis for the treatment. Clinical compliance has been found to be enhanced when the patient's wife or partner's support and cooperation is incorporated in the treatment plan. Treating a patient with a plant-based diet has essentially no adverse effects or contraindications, is cost effective, lowers the risk of, and can even help treat several common comorbidities such as metabolic syndrome, diabetes, coronary artery disease and hypertension.

\section{Epidemiology, Pathogenesis and Etiology}

Epidemiological studies of prostate cancer have strongly implicated diet as a major modulator of prostate cancer risk. Prostate cancer incidence and mortality varies among different geographic regions, with high prostate cancer risk in the United States and Europe, and low prostate cancer risk in Asia, especially in those following a low animal-food diet. When immigrants from low-risk regions move to high-risk regions, they typically adopt higher prostate cancer risks, particularly with cultural assimilation [1,2]. This likely reflects dietary differences: either dietary habits in high risk regions promote prostate cancer, dietary habits in low risk regions prevent prostate cancer, or 


\section{Cancer Therapy \& Oncology International Journal}

both. When examined in greater detail, the most consistent dietary association for prostate cancer appears to be intake of red meats and or animal fats $[3,4]$.

As an overall dietary pattern, the risk of prostate cancer was $54 \%$ greater in the nonvegetarians $(\mathrm{P}=0.03)$ than vegetarians [5]. This dietary pattern includes a diet rich in fruits and vegetables, elimination of animal derived saturated fats, and elimination of cooked meats. In another study researchers found that inverse associations were observed with dietary intake of plant foods, suggesting decreased risk with a plant-based diet [6]. In summarizing, the research on diet for primary and secondary prostate prevention, many believe "heart healthy equals prostate healthy" [7].

\section{Saturated Fat Consumption}

The type of fatty acid consumed, rather than total amount, may play an important role in prostate cancer development and progression [8]. A study found plasma saturated fatty acids to be positively associated with prostate cancer risk in a prospective cohort of 14,514 men of the Melbourne Collaborative Cohort Study [9].

Another study prospectively followed 384 men diagnosed with prostate cancer in Canada. Proportional hazards models were used to estimate the relative risk of dying from prostate cancer associated with terciles of fat intake, expressed as percent of dietary energy, while controlling for prognostic factors and total energy. The median duration of follow up was 5.2 years. After controlling for grade, clinical stage, initial treatment, age and total energy intake, the study found that saturated fat consumption was significantly associated with disease specific survival $(p=0.008)$. Compared to men in the lower tercile of saturated fat, those in the upper tercile had three times the risk of dying from prostate cancer (hazards ratio 3.13, 95\% confidence interval 1.28-7.67) [10]. Interestingly, another study found that eating more plant-based fat was associated with reduced prostate cancer risk [11].

\section{Cholesterol}

Cholesterol is required for proliferation in all animal cells and is especially important for membrane formation [12]. Serum cholesterol has been identified as an independent risk factor for prostate cancer. For instance, in a study published in 2014 , of 2,408 men scheduled for biopsy, serum cholesterol was independently associated with prediction of prostate cancer risk [13].

Many pre-clinical studies have shown that the accumulation of cholesterol contributes to the progression of prostate cancer [14-16]. It has been suggested that high cholesterol in circulation may be a risk factor for solid tumors, primarily through the upregulation of cholesterol synthesis, inflammatory pathways [17] and intratumoral steroidogenesis [18]. In prostate cancer, cholesterol may also act as a substrate for intratumoral androgen biosynthesis, even after androgen deprivation therapy via the CPY17A1 enzyme. This is expressed by castration resistant prostate cancer cells that de-novo synthesize androgens $[19,20]$.

Several lines of evidence link cholesterol metabolism and prostate cancer progression. Firstly, a positive association between serum cholesterol levels and high-grade prostate cancer has been described [21]. Secondly, in vivo xenograft and in vitro cancer progression models have identified numerous aberrations in regulators of cholesterol metabolism [22-25]. Thirdly, statin use as a cholesterol-lowering therapy has been associated with a lower risk of prostate cancer diagnosis [26], advanced disease [27], and mortality [28].

Usage of statin cholesterol-lowering drugs, post radical prostatectomy (RP), was significantly associated with reduced risk of biochemical recurrence in 1,146 radical prostatectomy patients [29]. Another study also showed that statins may reduce prostate cancer risk by lowering progression [30]. Although the mechanism has not been established, more recent studies also showed that a low high-density lipoprotein (HDL) cholesterol level was associated with a higher risk for prostate cancer and, thus, a higher HDL was protective [31-33].

However, a disturbing increase in the HGPCa (high grade prostate carcinoma) rate was observed in statin users who normalized their serum cholesterol [13]. These findings support the notion that a heart-healthy dietary intervention that lowers cholesterol may benefit prostate health, without any other risks, whereas the statin approach, while reducing the general risk, may increase the risk of high grade lesions. Vegetarians and vegans have lower total and LDL cholesterol levels on average $[34,35]$. Vegans, or total vegetarians, have the lowest levels.

\section{Persistent Organic Pollutants}

Persistent organic pollutants (POPs) are synthetic organic chemicals that have an intrinsic resistance to natural degradation processes and are therefore environmentally persistent and bioaccumulate through the food web. They include dioxins, furans, polychlorinated biphenyls (PCBs), and organochlorine pesticides, chemicals mainly created by industrial activities either intentionally or as by-products [36]. The introduction of POPs into the environment from anthropogenic activities resulted in their widespread dispersal and accumulation in soils and bodies of water, as well as in human and ecological food chains, where they are known to induce toxic effects.

There is evidence of long range transport of these substances to regions where they have never been used or produced, resulting in exposure of most human populations to POPs through consumption of fat-containing food such as fish, dairy products, and meat [37-39], with the highest POP concentrations being commonly found in fatty fish [36-42]. Due to their ubiquity in the environment and lipophilic properties, there is mounting concern over the potential risks of human exposure to POPs [37]. Total body concentrations of POPs showed positive associations 
with prostate cancer increasing cancer risk by $31 \%$ [43]. In a dose-response meta-analysis, $1 \mu \mathrm{g} / \mathrm{g}$ lipid of PCBs was found to be associated with a $49 \%$ increased risk of prostate cancer (OR 1.49, 95 \% CI 1.07, 2.06). Even one nanogram per gram lipid of trans-nonachlor still was found to be associated with approximately $2 \%$ increased risk of prostate cancer (OR $=1.02 / 1$ $\mathrm{ng} / \mathrm{g}$ lipid of trans-nonachlor, $95 \%$ CI 1.00, 1.03).

Some studies have found an even greater increased risk of prostate cancer with exposure to specific POPs. In one study, a greater than median concentration of one of the PCB congeners showed an increase 3.15 times and one chlordane type, transchlordane, showed a 3.49 times increased risk. In the group of case subjects with PSA levels greater than the median level of $16.5 \mathrm{ng} / \mathrm{mL}$, the increased risk was even higher [44]. The available evidence suggests that body concentrations of POPs are positively associated with prostate cancer risk, which implies valuable evidence for prostate cancer prevention [43].

\section{Heterocyclic Amines and Polycyclic Aromatic Hydrocarbons}

Cooking meat produces Heterocyclic Amines (HCAs) and Polycyclic Aromatic Hydrocarbons (PAHs). The fact that these are carcinogens is well established. Researchers found that high consumption of cooked, fried, or barbecued meats was associated with increased risk of prostate cancer $[45,46]$. Additionally, the ability of these food-borne carcinogens to induce prostate cancer has been studied [45-49].

\section{Inflammatory Response}

Most of the inflammation in the prostate is a consequence of damage to the prostate epithelium, which can be caused by dietary carcinogens, estrogens, and inflammatory oxidants [50]. Recently, molecular pathology insights have indicted chronic or recurrent epithelial cell injury, accompanied by innate and adaptive inflammatory responses, in the early steps of prostate cancer development.

As a consequence, dietary components capable of inducing such injury, such as the heterocyclic amines created by cooking meats, loom large as candidate prostate carcinogens, while dietary components able to limit cell and genome damage and/or attenuate prostate inflammation, may protect against prostate cancer development [51]. The best studied of these carcinogens for prostate cancer is 2-amino-1-methyl-6phenylimidazopyridine (PhIP), the most abundant of the more than 20 heterocyclic amines that can appear in cooked meats [51]. Diets rich in inducers of phase 2 metabolic enzyme expression, which activate the Keap1-Nrf2 pathway, both reduce carcinogen damage generally in animal models, and lower prostate cancer risk in human epidemiology studies [52-54].

\section{Insulin-like Growth Factor-I}

While research on IGF-I and prostate cancer has yielded somewhat inconsistent results, there are enough studies with positive results to warrant its inclusion here. One study found modestly lower IGF-I levels in vegan men. Mean serum IGF-I was 9\% lower in 233 vegan men than in 226 meat eaters and 237 vegetarians $(\mathrm{P}=0.002)$. Vegans had higher testosterone levels than vegetarians and meat-eaters, but this was offset by higher sex hormone binding globulin, and there were no differences between diet groups in free testosterone, androstanediol glucuronide or luteinizing hormone [55]. IGF-I may play an important role in the etiology of prostate cancer via its ability to interact with androgens to stimulate prostatic cell growth [56]. Chan et al. [57] found that men who subsequently developed prostate cancer had $8 \%$ higher serum IGF-I concentrations than men who remained healthy, suggesting that the $9 \%$ difference we observed is large enough to significantly alter prostate cancer risk [57]. An increased risk from high IGF-1 and low binding protein (IGFBP-1) was confirmed just recently [58].

\section{Risk reduction with Specific Foods}

The foods with the highest levels of phase 2 enzyme inducers, such as the isothiocyanate sulforaphane, are the cruciferous vegetables, such as broccoli, Brussels sprouts, cauliflower, and others. In a study of normal human volunteers, intake of cruciferous vegetables reduced PhIP adduction to DNA in response to a cooked meat meal [59]. The mechanism(s) by which dietary components, inherited susceptibility, and sex steroid hormones cause epithelial damage and/or drive inflammatory processes that lead to cancer as men age, if better understood, could provide new opportunities for prostate cancer prevention, improved prostate cancer screening strategies, and perhaps even better prostate cancer treatment outcomes. However, it is important to note that a vegetarian diet results in lower levels of C-reactive protein $[60,61]$.

Several epidemiologic studies found inverse relationships between total fruit and vegetable intake [62], including cruciferous vegetable intake, and PCa risk $[63,64]$. In addition to the cruciferous vegetables discussed above, several other foods have been investigated, in particular green tea, tomato sauce and allium vegetables (onions, garlic, and scallions). In a prospective randomized preprostatectomy trial, men consuming brewed green tea prior to surgery had increased levels of green tea polyphenols in their prostate tissue [65]. In a small proof of principle trial with 60 men, daily supplementation of $600 \mathrm{mg}$ green tea catechin extract reduced PCa incidence by $90 \%$ (3\% versus $30 \%$ in the placebo group) [66]. Another small trial also showed that EGCG supplement resulted in a significant reduction in PSA, hepatocyte growth factor and vascular endothelial growth factor in men with prostate cancer [67]. These studies suggest green tea polyphenols may lower prostate incidence and reduce PCa progression.

Two short term preprostatectomy trials using tomato sauce or lycopene supplementation demonstrated lycopene uptake in prostate tissue and antioxidant and potential anticancer effects $[68,69]$. While several clinical trials suggested an inverse 


\section{Cancer Therapy \& Oncology International Journal}

relationship between lycopene supplementation, PSA levels and decreases in cancer related symptoms [70,71].

In a case study of several hundred subjects with incident histologically-confirmed prostate cancer and male control subjects, men in the highest of three intake categories of total allium vegetables ( $>10.0 \mathrm{~g} /$ day) had a statistically significantly lower risk (odds ratio [OR] $=0.51,95 \%$ confidence interval $[\mathrm{CI}]$ $=0.34$ to 0.76 ; $\mathrm{P}($ trend $)<.001)$ of prostate cancer than those in the lowest category $(<2.2 \mathrm{~g} /$ day). Similar comparisons between categories showed reductions in risk for men in the highest intake categories for garlic $(\mathrm{OR}=0.47,95 \% \mathrm{CI}=0.31$ to 0.71 ; $\mathrm{P}($ trend $)<.001)$ and scallions $(\mathrm{OR}=0.30,95 \% \mathrm{CI}=0.18$ to 0.51 ; $\mathrm{P}($ trend $)<.001)$. The reduced risk of prostate cancer associated with allium vegetables was independent of body size, intake of other foods, and total calorie intake, and was more pronounced for men with localized than with advanced prostate cancer [72].

\section{Clinical Intervention}

An important study examined whether comprehensive changes in diet to a plant-based diet (along with stress management) would affect the progression of prostate cancer, as measured by serial prostate specific antigen (PSA), treatment trends, and serum stimulated LNCaP cell growth, in men with early, biopsy-proven prostate cancer (Gleason score less than 7, PSA 4 to $10 \mathrm{ng} / \mathrm{ml}$, stages T1 and T2) [73]. Patient recruitment was limited to men who had chosen not to undergo any conventional treatment. The choice to perform watchful waiting was considered clinically reasonable in these men. The interventional diet consisted of fruits, vegetables, whole grains, legumes and soy products, with approximately $10 \%$ of calories from fat.

After one year, adherence to the intervention was $95 \%$ in the experimental group. There were no adverse events attributable to dietary intervention, and none of the patients in the experimental group required intervention with standard treatment, whereas $12 \%$ of the control group did. Serum from experimental group patients inhibited LNCaP cell growth by $70 \%$, whereas serum from control group patients inhibited growth by only $9 \%$ ( $\mathrm{p}<$ [1] 0.001). Serum PSA decreased an average of $0.25 \mathrm{ng} / \mathrm{ml}$ or $4 \%$ of the baseline average in the experimental group, but it showed an average increase of $0.38 \mathrm{ng} / \mathrm{ml}$ or $6 \%$ of the baseline average in the control group $(\mathrm{p}<0.016)$.

Patients with low grade prostate cancer were able to make and maintain comprehensive lifestyle changes for at least one year, resulting in significant decreases in serum PSA and a lower likelihood of needing standard treatment. In addition, substantially decreased growth of LNCaP prostate cancer cells was seen, when such cells were incubated in the presence of serum from those who made lifestyle changes. These findings suggest that intensive changes in diet and lifestyle may beneficially affect the progression of early prostate cancer. The observation that changes in PSA and in LNCaP cell growth were significantly related to the extent by which participants had changed their lifestyle, further supports the hypothesis that intensive changes in diet may affect the progression of prostate cancer.

A two-year follow up study revealed that only $5 \%$ of the experimental group required standard treatment, versus almost $25 \%$ in the control group, in addition to the $12 \%$ during the first year [74]. The authors conclude that patients with early stage prostate cancer choosing active surveillance might be able to avoid or delay conventional treatment for at least two years by making changes in their diet and lifestyle.

A pilot study was conducted to examine changes in prostate gene expression in a unique population of men with low risk prostate cancer. These men had declined immediate surgery, hormonal therapy, or radiation, and participated in an intensive nutritional intervention (along with stress reduction activities) to a plant-based diet, while undergoing careful surveillance for tumor progression. Gene expression profiles were obtained from 30 participants, pairing RNA samples from control prostate needle biopsy taken before intervention to RNA from the same patient's 3-month post intervention biopsy. Two class paired analysis of global gene expression using significance analysis of microarrays detected 48 up regulated and 453 down regulated transcripts after the intervention. Pathway analysis identified significant modulation of biological processes that have critical roles in tumorigenesis, including protein metabolism and modification, intracellular protein traffic, and protein phosphorylation (all $\mathrm{P}<0.05$ ). Intensive changes in nutrition may modulate gene expression in the prostate [75]. This study provides molecular hypotheses that may help explain some of the effects of comprehensive lifestyle changes.

\section{Clinical Considerations}

Evidence indicates that a healthy diet may improve overall clinical outcomes and quality of life in cancer survivors [76,77]. In one study, greater exercise and better diet quality were associated with better physical quality of life outcomes (eg, better vitality and physical functioning; $\mathrm{P}<.05$ ) in prostate cancer patients [76].

Many men make positive dietary changes after PCa diagnosis, which are perceived by men and their partners to bring psychological and general health benefits and could help future dietary intervention trials. Men and their partners desire more and better dietary information that may support PCa survivorship, particularly among those embarking on active surveillance/monitoring programs. There are opportunities for healthcare professionals to support PCa patients both clinically and psychologically, by the routine integration of healthy eating advice into survivorship care plans [77].

One study found that prostate cancer patients' partners played a significant and multi-faceted role in their diets, often referring to dietary decisions being made jointly. While 
partners more often assumed responsibility for food purchasing and preparation, decisions about meal choices were mostly jointly made. Consequently, men typically described having considerable control or responsibility over their diet. Interest in dietary advice was high among men both at elevated risk and men diagnosed with PCa, and their partners [77]. This study clearly indicates the value of soliciting the cooperation of the patient's partner when prescribing dietary changes in prostate cancer patients.

\section{Discussion}

It seems that there are several factors involved in the increased incidence of prostate cancer in men who consume animal derived foods. Lipophilic persistent organic pollutants bioconcentrate to significant levels in the adipose tissue of animals thus dosing their consumer with substantial amounts. These carcinogens play a role in raising the risk of prostate cancer. Polycyclic aromatic hydrocarbons and heterocyclic amines, formed when meat is cooked, cause a chronic inflammation of the prostate, thus playing a role in the development of malignant neoplasia. Consuming animal fat increases exposure to persistent organic pollutants and is one way that they raise the risk of prostate cancer. Another way is that the saturated fats that animal fats contain raise serum cholesterol, which is now implicated in prostate cancer as well. On the other hand, several plant foods have been shown to lower the risk of prostate cancer. The mechanisms by which these factors induce a malignant transformation or exert a chemoprotective effect are being investigated and have begun to yield some evidence by which they achieve of their effects.

In low-grade early-stage prostate cancer, a low-fat plantbased diet seems to have proven beneficial over a period of two years. Strengthening the findings was that the greater the level of patient adherence, the stronger the tumor suppressing effect, thus furthering strengthening the case for dietary intervention. Changes in gene expression were noted in other studies.

\section{Conclusion}

The plant-based diet, or vegan diet as it is also commonly known, is considered safe for all age groups by the American Academy of Nutrition and Dietetics, with recognized effects of lowering the risk of a number of diseases including ischemic heart disease and diabetes [78] which many prostate cancer patients, or those at risk for prostate cancer, either have or are at risk for, and even help treat those diseases. With no adverse effects noted and no contraindications, dietary intervention would offer a cost-effective way to reduce the risk of prostate cancer, and to treat those cases where watchful waiting is prescribed. It would likely enhance current standard treatments, while also lowering the risk of common comorbidities.

Future research is needed to further elucidate the mechanisms by which animal-derived foods induce prostate cancer and plant foods exert their chemoprotective effect. Further research is also needed to determine which plant foods, in addition to those already identified, have substantial chemoprotective effects. Research is needed to determine the efficacy of plant-based diets in high grade tumors, and advanced stages of prostate cancer with both high and low-grade tumors. It also remains to be determined how important a risk factor the consumption of animal products is, compared to other risk factors such as age and family history.

\section{Conflict of Interest}

The authors state no conflicts of interest or funding sources.

\section{References}

1. Haenszel W, Kurihara M (1968) Studies of Japanese migrants. I. Mortality from cancer and other diseases among Japanese in the United States. J Natl Cancer Inst 40(1): 43-68.

2. Shimizu H, Ross R, Bernstein L, Yatani R, Henderson B, et al. (1991) Cancers of the prostate and breast among Japanese and white immigrants in Los Angeles County. Br J Cancer 63(6): 963-966.

3. Giovannucci E, Rimm E, Colditz G, Stampfer MJ, Ascherio A, et al. (1993) A prospective study of dietary fat and risk of prostate cancer. J Natl Cancer Inst 85(19): 1571-1579.

4. Le Marchand L, Kolonel L, Wilkens L, Myers B, Hirohata T (1994) Animal fat consumption and prostate cancer: a prospective study in Hawaii. Epidemiology 5(3): 276-282.

5. Fraser GE (1999) Associations between diet and cancer, ischemic heart disease, and all-cause mortality in non-Hispanic white California Seventh-day Adventists. Am J Clin Nutr 70(3): 532s-538s.

6. Stacewicz-Sapuntzakis M, Borthakur G, Burns J, Bowen P (2008) Correlations of dietary patterns with prostate health. Mol Nutr Food Res 52(1): 114-130.

7. Lin P, Aronson W, Freedland S (2015) Nutrition, dietary interventions and prostate cancer: the latest evidence. BMC Medicine 13: 3.

8. Ohwaki K, Endo F, Kachi Y, Hattori K, Muraishi O, et al. (2012) Relationship between dietary factors and prostate-specific antigen in healthy men. Urol Int 89(3): 270-274.

9. Bassett J, Severi G, Hodge A, MacInnis RJ, Gibson RA, et al. (2013) Plasma phospholipid fatty acids, dietary fatty acids and prostate cancer risk. Int J Cancer 133(8): 1882-1891.

10. Fradet Y, Meyer F, Bairati I, Shadmani R, Moore L (1999) Dietary fat and prostate cancer progression and survival. Eur Urol 35(5-6): 388-391.

11. Richman E, Kenfield S, Chavarro J, Stampfer MJ, Giovannucci EL, et al. (2013) Fat intake after diagnosis and risk of lethal prostate cancer and all-cause mortality. JAMA Intern Med 173(14): 1316-1326.

12. Pelton K, Freeman M, Solomon K (2012) Cholesterol and prostate cancer. Curr Opin Pharmacol 12(6): 751-759.

13. Morote J, Celma A, Planas J, Placer J, de Torres I, et al. (2014) Role of serum cholesterol and statin use in the risk of prostate cancer detection and tumor aggressiveness. Int J Mol Sci 15(8): 13615-13623.

14. Yue S, Li J, Lee S, Lee HJ, Shao T, et al. (2014) Cholesteryl ester accumulation induced by PTEN loss and PI3K/AKT activation underlies human prostate cancer aggressiveness. Cell Metab 19(3): 393-406.

15. Sun Y, Sukumaran P, Varma A, Derry S, Sahmoun A, et al. (2014) Cholesterol-induced activation of TRPM7 regulates cell proliferation, migration, and viability of human prostate cells. Biochem Biophys Acta 1843(9): 1839-1850. 


\section{Cancer Therapy \& Oncology International Journal}

16. Murai T (2015) Cholesterol lowering: role in cancer prevention and treatment. Biol Chem 396(1): 1-11.

17. Zhuang L, Kim J, Adam R, Solomon K, Freeman M (2005) Cholesterol targeting alters lipid raft composition and cell survival in prostate cancer cells and xenografts. J Clin Invest 115(4): 959-968.

18. Mostaghel E, Solomon K, Pelton K, Freeman M, Montgomery R (2012) Impact of circulating cholesterol levels on growth and intratumoral androgen concentration of prostate tumors. PLoS One 7(1): e30062.

19. Montgomery R, Mostaghel E, Vessella R, Hess Dl, Kalhorn TF, et al. (2008) Maintenance of intratumoral androgens in metastatic prostate cancer: a mechanism for castration-resistant tumor growth. Cancer Res. 68(11): 4447-4454.

20. Stopsack K, Gerke T, Sinnott J, Penney KL, Tyekucheva S, et al. (2016) Cholesterol metabolism and prostate cancer lethality. Cancer Res 76(16): 4785-4790.

21. Platz E, Clinton S, Giovannucci E (2008) Association between plasma cholesterol and prostate cancer in the PSA. Int J Cancer 123(7): 16931698.

22. Leon C, Locke J, Adomat H, Etinger SL, Twiddy AL, et al. (2010) Alterations in cholesterol regulation contribute to the production of intratumoral androgens during progression to castration-resistant prostate cancer in a mouse xenograft model. Prostate 70(4): 390-400.

23. Lee B, Taylor M, Robinet P, Smith JD, Schweitzer J, et al. (2013) Dysregulation of cholesterol homeostasis in human prostate cancer through loss of ABCA1. Cancer Res 73(3): 1211-1218.

24. Twiddy A, Cox M, Wasan K (2012) Knockdown of scavenger receptor class B type I reduces prostate specific antigen secretion and viability of prostate cancer cells. Prostate 72(9): 955-965.

25. Murtola T, Syvälä H, Pennanen P, Bläuer M, Solakivi T, et al. (2012) The importance of LDL and cholesterol metabolism for prostate epithelial cell growth. PLoS One 7(6): e39445.

26. Farwell W, D’Avolio L, Scranton R, Lawler E, Gaziano J (2011) Statins and prostate cancer diagnosis and grade in a veterans population. Natl Cancer Inst 103(11): 885-892.

27. Platz E, Leitzmann M, Visvanathan K, Rimm EB, Stampfer MJ, et al (2006) Statin drugs and risk of advanced prostate cancer. J Natl Cancer Inst 98(24): 1819-1825.

28. Yu O, Eberg M, Benayoun S, Aprikian S, Batist G, et al. (2014) Use of statins and the risk of death in patients with prostate cancer. J Clin Oncol 32(1): 5-11.

29. Allott E, Howard L, Cooperberg M, Kane CJ, Aronson WJ, et al. (2014) Postoperative statin use and risk of biochemical recurrence following radical prostatectomy: results from the Shared Equal Access Regional Cancer Hospital (SEARCH) database. BJU Int 114(5): 661-666.

30. Jespersen C, Nørgaard M, Friis S, Skriver C, Borre M (2014) Statin use and risk of prostate cancer: A Danish population-based case-control study, 1997-2010. Cancer Epidemiol 38(1): 42-47.

31. Meyers C, Kashyap M (2004) Pharmacologic elevation of highdensity lipoproteins: recent insights on mechanism of action and atherosclerosis protection. Curr Opin Cardiol 19(4): 366-373.

32. Xia P, Vadas M, Rye K, Barter P, Gamble JR (1999) High density lipoproteins (HDL) interrupt the sphingosine kinase signaling pathway. A possible mechanism for protection against atherosclerosis by HDL. J Biol Chem 274(46): 33143-33147.

33. Kotani K, Sekine Y, Ishikawa S, Ikpot I, Suzuki K, et al. (2013) Highdensity lipoprotein and prostate cancer: an overview. J Epidemiol 23(5): 313-319.

34. Thorogood M, Carter R, Benfield L, McPherson K, Mann JI (1987)
Plasma and lipoprotein cholesterol concentrations in people with different diets in Britain. Br Med J Clin Res Ed 295(6594): 351-353.

35. Haddad EH, Berk LS, Kettering JD, Hubbard RW, Peters WR (1999) Dietary intake and biochemical, hematologic, and immune status of vegans compared with nonvegetarians. Am J Clin Nutr 70(3 Suppl): 586S-593S

36. Bergkvist C, Oberg M, Appelgren M, Becker W, Aune M, et al. (2008) Exposure to dioxin-like pollutants via different food commodities in Swedish children and young adults. Food Chem Toxicol 46(11): 33603367.

37. Dougherty C, Henricks Holtz S, Reinert J, Panyacosit L, Axelrad D, et al. (2000) Dietary exposures to food contaminants across the United States. Environ Res 84(2): 170-185.

38. Walker P, Rhubart-Berga P, McKenzie S, Kelling K, Lawrence R (2005) Public health implications of meat production and consumption. Public Health Nutr 8(4): 348-356.

39. Sasamoto T, Ushio F, Kikutani N, Saitoh Y, Yamaki Y, et al. (2006) Estimation of 1999-2004 dietary daily intake of PCDDs, PCDFs and dioxin-like PCBs by a total diet study in metropolitan Tokyo, Japan. Chemosphere 64(4): 634-641.

40. Bocio A, Domingo J (2005) Daily intake of polychlorinated dibenzo-pdioxins/polychlorinated dibenzofurans (PCDD/PCDFs) in foodstuffs consumed in Tarragona, Spain: a review of recent studies (2001-2003) on human PCDD/PCDF exposure through the diet. Environ Res 97(1): $1-9$.

41. Schecter A, Colacino J, Haffner D, Patel K, Opel M, et al. (2010) Perfluorinated compounds, polychlorinated biphenyls, and organochlorine pesticide contamination in composite food samples from Dallas, Texas, USA. Environ Health Perspect 118(6): 796-802.

42. Darnerud P, Atuma S, Aune M, Bierselius R, Glynn A, et.al. (2006) Dietary intake estimations of organohalogen contaminants (dioxins, PCB, PBDE and chlorinated pesticides, e.g. DDT) based on Swedish market basket data. Food Chem Toxicol 44(9): 1597-1606.

43. Lim J, Park S, Jee S, Park H (2015) Body concentrations of persistent organic pollutants and prostate cancer: a meta-analysis. Environ Sci Pollut Res Int 22(15): 11275-11284.

44. Hardell L, Andersson S, Carlberg M, Bohr L, Van Bavel B, et al. (2006) Adipose tissue concentrations of persistent organic pollutants and the risk of prostate cancer. J Occup Environ Med 48(7): 700-707.

45. Cross A, Peters U, Kirsh V, Andriole GL, Reding D, et al. (2005) A prospective study of meat and meat mutagens and prostate cancer risk. Cancer Res 65(24): 11779-11784.

46. Sinha R, Park Y, Graubard B, Leitzmann MF, Hollenbeck A, et al. (2009) Meat and meat-related compounds and risk of prostate cancer in a large prospective cohort study in the United States. Am J Epidemiol. 170(9): 1165-1177.

47. Powell J, Ghotbaddini M (2014) Cancer-promoting and inhibiting effects of dietary compounds: role of the aryl hydrocarbon receptor (AhR). Biochem Pharmacol (Los Angel) 3(1).

48. Sander A, Linseisen J, Rohrmann S (2011) Intake of heterocyclic aromatic amines and the risk of prostate cancer in the EPIC-Heidelberg cohort. Cancer Causes Control 22(1): 109-114.

49.Zheng W, Lee S (2009) Well-done meat intake, heterocyclic amine exposure, and cancer risk. Nutr Cancer 61(4): 437-446.

50. De Marzo A, Platz E, Sutcliffe S, Grönberg H, Drake CG, et al. (2007) Inflammation in prostate carcinogenesis. Nat Rev Cancer 7(4): 256269.

51. Nelson W, Demarzo A, Yegnasubramanian S (2014) The diet as a cause of human prostate cancer. Cancer Treat Res 159: 51-68. 


\section{Cancer Therapy \& Oncology International Journal}

52. Ahn YH, Hwang Y, Liu H, Wang XJ, Zhang Y, et al. (2010) Electrophilic tuning of the chemoprotective natural product sulforaphane. Proc Natl Acad Sci USA 107(21): 9590-9595.

53. Cohen J, Kristal A, Stanford J (2000) Fruit and vegetable intakes and prostate cancer risk. J Natl Cancer Inst 92(1): 61-68.

54. Dinkova-Kostova A, Talalay P (2008) Direct and indirect antioxidant properties of inducers of cytoprotective proteins. Mol Nutr Food Res 52(Suppl 1): S128-S138.

55. Allen N, Appleby P, Davey G, Key TJ (2000) Hormones and diet: low insulin-like growth factor-I but normal bioavailable androgens in vegan men. Br J Cancer 83(1): 95-97.

56. Cohen P, Peehl D, Rosenfeld R (1994) IGF axis in the prostate. Horm Metab Res 26(2): 81-84.

57. Chan J, Stampfer M, Giovannucci E, Gann PH, Ma J, et al. (1998) Plasma insulin-like growth factor-I and prostate cancer risk: a prospective study. Science 279(5350): 563-566.

58. Cao Y, Nimptsch K, Shui I, Platz EA, Wu K, et al. (2015) Prediagnostic plasma IGFBP-1, IGF-1 and risk of prostate cancer. Int J Cancer 136(10): 2418-2426.

59. Walters D, Young P, Agus C, Knize MG, Boobis AR, et al. (2004) Cruciferous vegetable consumption alters the metabolism of the dietary carcinogen 2-amino-1-methyl-6-phenylimidazo[4,5-b] pyridine (PhIP) in humans. Carcinogenesis 25(9): 1659-1669.

60. Krajcovicova-Kudlackova M, Blazicek P (2005) C-reactive protein and nutrition. Bratisl Lek Listy 106(11): 345-347.

61. Chen C, Lin Y, Lin TK, Lin CT, Chan BC, et al. (2008) Total cardiovascular risk profile of Taiwanese vegetarians. Eur J Clin Nutr 62(1): 138-144.

62. Askari F, Parizi M, Jessri M, Rashidkhani B (2014) Fruit and vegetable intake in relation to prostate cancer in Iranian men: a case-control study. Asian Pac J Cancer Prev 15(13): 5223-5227.

63. Liu B, Mao Q Cao M, Xie L (2012) Cruciferous vegetables intake and risk of prostate cancer: a meta-analysis. Int J Urol 19(2): 134-141.

64. Richman E, Carroll P, Chan J (2012) Vegetable and fruit intake after diagnosis and risk of prostate cancer progression. Int J Cancer 131(1): 201-210.

65. Wang P, Aronson W, Huang M, Zhang Y, Lee RH (2010) Green tea polyphenols and metabolites in prostatectomy tissue: implications for cancer prevention. Cancer Prev Res (Phila) 3(8): 985-993.

66. Kurahashi N, Sasazuki S, Iwasaki M, Inoue M, Tsugane S, et al. (2008) Green tea consumption and prostate cancer risk in Japanese men: a prospective study. Am J Epidemiol 167(1): 71-77.
67. McLarty J, Bigelow R, Smith M, Elmajian D, Ankem M, et al. (2009) Tea polyphenols decrease serum levels of prostate-specific antigen, hepatocyte growth factor, and vascular endothelial growth factor in prostate cancer patients and inhibit production of hepatocyte growth factor and vascular endothelial growth factor in vitro. Cancer Prev Res (Phila) 2(7): 673-82.

68. Gann P, Ma J, Giovannucci E, Willett W, Sacks FM, et al. (1999) Lower prostate cancer risk in men with elevated plasma lycopene levels: results of a prospective analysis. Cancer Res 59(6): 1225-1230.

69. Kucuk O, Sarkar F, Djuric Z, Sakr W, Pollak MN, et al. (2002) Effects of lycopene supplementation in patients with localized prostate cancer. Exp Biol Med (Maywood) 227(10): 881-885.

70. Chen L, Stacewicz-Sapuntzakis M, Duncan C, Sharifi R, Ghosh L, et al. (2001) Oxidative DNA damage in prostate cancer patients consuming tomato sauce-based entrees as a whole-food intervention. J Natl Cancer Inst 93(24): 1872-1879.

71. Van Breemen R, Sharifi R, Viana M, Pajkovic N, Zhu D, et al. (2011) Antioxidant effects of lycopene in African American men with prostate cancer or benign prostate hyperplasia: a randomized, controlled trial. Cancer Prev Res (Phila) 4(5): 711-718.

72. Hsing A, Chokkalingam A, Gao Y, Madigan MP, Deng J, et al. (2002) Allium vegetables and risk of prostate cancer: a population-based study. J Natl Cancer Inst 94(21): 1648-1651.

73. Ornish D, Weidner G, Fair W, Marlin R, Pettengill EB, et al. (2005) Intensive lifestyle changes may affect the progression of prostate cancer. J Urol 174(3): 1065-1109.

74. Frattaroli J, Weidner G, Dnistrian A, Kemp C, Daubenmier JJ, et al. (2008) Clinical events in prostate cancer lifestyle trial: results from two years of follow-up. Urology 72(6): 1319-1323.

75. Ornish D, Magbanua M, Weidner G, Weinberg V, Kemp C, et al. (2008) Changes in prostate gene expression in men undergoing an intensive nutrition and lifestyle intervention. Proc Natl Acad Sci USA 105(24): 8369-8374.

76. Mosher C, Sloane R, Morey M, Snyder DC, Cohen HJ, et al. (2009) Associations between lifestyle factors and quality of life among older long-term breast, prostate, and colorectal cancer survivors. Cancer 115(17): 4001-4009.

77. Avery K, Donovan J, Horwood J, Neal DE, Hamdy FC, et al. (2014) The importance of dietary change for men diagnosed with and at risk of prostate cancer: a multi-centre interview study with men, their partners and health professionals. BMC Fam Pract 15: 81.

78. Melina V, Craig W, Levin S (2016) Position of the academy of nutrition and dietetics: vegetarian diets. J Acad Nutr Diet 116(12): 1970-1980.
Your next submission with Juniper Publishers will reach you the below assets

- Quality Editorial service

- Swift Peer Review

- Reprints availability

- E-prints Service

- Manuscript Podcast for convenient understanding

- Global attainment for your research

- Manuscript accessibility in different formats ( Pdf, E-pub, Full Text, Audio)

- Unceasing customer service

Track the below URL for one-step submission https://juniperpublishers.com/online-submission.php 